\title{
Extreme body mass index is associated with poor survival outcomes after radical cystectomy: a retrospective cohort study in a Chinese population
}

\author{
Xin Huang ${ }^{1,2}$, Shenye Jin ${ }^{3}$, Shenghua Liu ${ }^{3}$, Jiang Geng ${ }^{1,3}$ \\ ${ }^{1}$ Clinical Medical College of Shanghai Tenth People's Hospital, Nanjing Medical University, Nanjing, China; ${ }^{2}$ Department of Urology, Liyang \\ People's Hospital, Liyang, China; ${ }^{3}$ Department of Urology, Shanghai Tenth People's Hospital, Tongji University, Shanghai, China \\ Contributions: (I) Conception and design: S Liu, J Geng; (II) Administrative support: J Geng; (III) Provision of study materials or patients: J Geng; (IV) \\ Collection and assembly of data: X Huang, S Jin, S Liu; (V) Data analysis and interpretation: X Huang, S Jin; (VI) Manuscript writing: All authors; (VII) \\ Final approval of manuscript: All authors. \\ Correspondence to: Jiang Geng. No. 301 Middle Yanchang Road, Shanghai 200072, China. Email: gengjiangsn@sina.com.
}

\begin{abstract}
Background: Body mass index (BMI) has been evidenced to be a significant prognostic factor in multiple cancers. This retrospective study aimed to investigate the association between BMI and survival outcomes after radical cystectomy $(\mathrm{RC})$ in patients with bladder cancer (BCa).

Methods: Clinical and pathological parameters of patients who were diagnosed with $\mathrm{BCa}$ and received RC between 2010 and 2018 were collected. The associations between BMI at surgery and clinicopathological features were examined. The prognostic value of BCa for overall survival (OS) and cancer-specific survival (CSS) was examined using the Kaplan-Meier method and Cox regression models.

Results: Among the 217 patients enrolled in this study, 13 (6.0\%), 121 (55.8\%), 60 (27.6\%), and 23 (10.6\%) had a BMI value of $<18.5 \mathrm{~kg} / \mathrm{m}^{2}$ (underweight), $18.5-23.9 \mathrm{~kg} / \mathrm{m}^{2}$ (normal), $24-27.9 \mathrm{~kg} / \mathrm{m}^{2}$ (overweight), and $\geq 28 \mathrm{~kg} / \mathrm{m}^{2}$ (obese), respectively. Underweight and obese patients tended to have poorer survival after RC than normal and overweight patients $(\mathrm{P}<0.05)$. Multivariable Cox regression revealed that extreme BMI was an independent predictor of both OS (BMI $<18.5$ vs. $18.5-27.9 \mathrm{~kg} / \mathrm{m}^{2}$, OR =2.675, 95\% CI: $1.131-6.327$, $\mathrm{P}=0.025 ; \mathrm{BMI} \geq 28$ vs. $18.5-27.9 \mathrm{~kg} / \mathrm{m}^{2}, \mathrm{OR}=3.693,95 \%$ CI: $\left.1.589-8.583, \mathrm{P}=0.002\right)$ and $\mathrm{CSS}(\mathrm{BMI}<18.5$ vs. $18.5-27.9 \mathrm{~kg} / \mathrm{m}^{2}, \mathrm{OR}=3.012,95 \%$ CI: $1.180-7.687, \mathrm{P}=0.021 ; \mathrm{BMI} \geq 28$ vs. $18.5-27.9 \mathrm{~kg} / \mathrm{m}^{2}, \mathrm{OR}=3.801$, 95\% CI: 1.526-9.469, $\mathrm{P}=0.004)$, along with tumor stage and urinary diversion type.

Conclusions: Being underweight or obese is associated with a poor prognosis in patients with $\mathrm{BCa}$ undergoing RC. For patients who are preparing to undergo RC for BCa, controlling the BMI index through diet or exercise before surgery may contribute to the surgical curative effect and an improved prognosis.
\end{abstract}

Keywords: Bladder cancer (BCa); body mass index (BMI); radical cystectomy; prognosis; survival

Submitted Sep 18, 2021. Accepted for publication Oct 20, 2021.

doi: $10.21037 /$ tau-21-871

View this article at: https://dx.doi.org/10.21037/tau-21-871

\section{Introduction}

Bladder cancer $(\mathrm{BCa})$ is one of the most common cancers affecting the urinary system and has high morbidity and relapse rates (1). An estimated 573,278 new cases of $\mathrm{BCa}$ and 212,536 deaths from BCa occurred worldwide in $2020(1,2)$. Over recent decades, much attention has been dedicated to establishing risk factors associated with the incidence and prognosis of BCa. Cigarette smoking, occupational exposure to aromatic amines, and a familial history of BCa have been well established as significant factors associated with $\mathrm{BCa}(3)$.

Body weight is a basic information for evaluating the physical condition of a patient, which is usually affected by living habits, hormone levels, and genetic factors. 
Excess body weight, which is commonly measured using body mass index (BMI), has been linked to the prognosis of various cancers, including esophageal, pancreatic, colorectal, endometrial, and prostate cancer (4-8). However, a conclusion on the association of BMI with $\mathrm{BCa}$ has yet to be reached, and the current guidelines do not consider BMI to be a risk factor for the disease (9-11). Although several studies have reported that obesity might be a poor prognostic factor for patients with advanced $\mathrm{BCa}$ following radical cystectomy $(\mathrm{RC})(12,13)$, recent studies have found no such correlation $(14,15)$.

To our knowledge, most studies investigating the association between body mass and oncologic outcomes after RC to date were performed in Western populations, and there is a dearth of research in Asian patients. Due to genetic and dietary differences, the Chinese cutoff points for overweight and obesity differ from those used in Western countries. Therefore, illuminating the association between BMI and oncologic outcomes based on a Chinese population would be extremely valuable. In this study, we retrospectively analyzed data from patients with $\mathrm{BCa}$ who underwent RC in a Chinese hospital and evaluated the association between BMI value and survival outcomes. We present the following article in accordance with the STROBE reporting checklist (available at https://dx.doi. org/10.21037/tau-21-871).

\section{Methods}

\section{Study participants and design}

Consecutive patients who were diagnosed with $\mathrm{BCa}$ and underwent RC in Shanghai Tenth People's Hospital between January 2010 and June 2018 were enrolled in this study. According to the European Association of Urology (EAU) guidelines, indications for RC included muscleinvasive $\mathrm{BCa}$ or high-risk non-muscle invasive $\mathrm{BCa}$. Patients who received neoadjuvant chemotherapy or radiotherapy were excluded.

Patients' medical records were reviewed retrospectively for clinical and pathological information, including age, sex, tumor stage, size, tumor grade, histology, lymphovascular invasion, and Charlson Comorbidity Index (CCI), measured according to the standardized International Classification of Diseases, Ninth Revision (16).

Height and weight were measured at admission, and a patient's BMI was calculated by dividing their weight in kilograms by the square of their height in meters $\left(\mathrm{kg} / \mathrm{m}^{2}\right)$.
Since all the patients were from China, the BMI cut-offs were set according to the Chinese criteria (17), as follows: underweight (BMI $<18.5 \mathrm{~kg} / \mathrm{m}^{2}$ ), normal (BMI 18.5 $-23.9 \mathrm{~kg} / \mathrm{m}^{2}$ ), overweight (BMI $24-27.9 \mathrm{~kg} / \mathrm{m}^{2}$ ), and obese (BMI $\geq 28 \mathrm{~kg} / \mathrm{m}^{2}$ ). This study was conducted in accordance with the Declaration of Helsinki (as revised in 2013) and was approved by the Ethics Committee of Shanghai Tenth People's Hospital (SHSY-IEC-4.1/20-24/01). Informed consent was taken from all individual participants.

\section{Surgical procedure and pathological evaluation}

Each patients underwent RC and pelvic lymph node dissection. Three urinary diversion methods were employed: cutaneous ureterostomy, ileal conduit, and orthotopic bladder substitution (Studer pouch). Tumor grade was evaluated according to the 2004 World Health Organization (WHO) classification by a single group of pathology doctors in Pathology Department of our hospital. Pathological stage was reassigned according to the 2010 American Joint Committee on Cancer TNM staging system. The definition of lymphovascular invasion was the presence of tumor cells in the lymphatic vessels and in the vascular walls.

\section{Follow-up}

Patients were followed up at 3-month intervals during the first 2 years after RC, and every 6 months thereafter. Follow-up consisted of medical history review, physical examination, blood laboratory tests, and urine sedimentation. Imaging examinations included computed tomography of the chest, abdomen and pelvis, and bone scanning, which were performed at 6 and 12 months postoperatively, and annually thereafter. Patients were followed until death or the cut-off date (November 30, 2018). The study endpoints were overall survival (OS) and cancer-specific survival (CSS). OS was defined as the length of time from the start of cystectomy to the date of any-cause death. CSS was defined as the length of time from the start of cystectomy to the date of death from BCa. The median follow-up period was 53 months (range, 4-112 months).

\section{Statistical analysis}

Clinicopathological variables were compared between four BMI groups (underweight, normal, overweight, and obese). Differences in clinical and pathological characteristics 


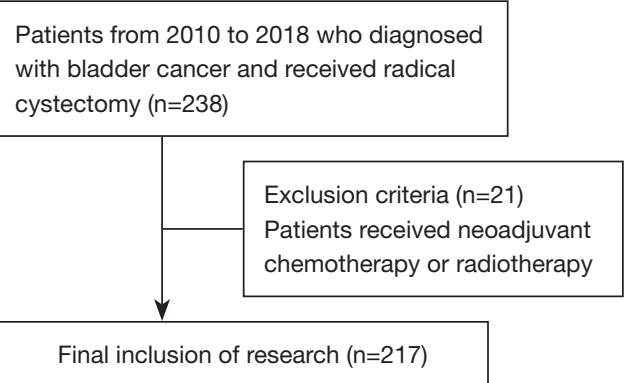

Figure 1 Flow chart of the study population enrolment.

between groups were estimated using Student's $t$-test, Wilcoxon signed-rank test, and Chi-square test. Then, the patients were divided into two groups: the underweight/ obese group and normal/overweight group. Kaplan-Meier survival curves were generated for OS and CSS in these two BMI groups, and compared using the log-rank test. To identify predictive factors of OS and CSS, univariable and multivariate Cox regression models were performed using all the variables collected. All statistical tests were twotailed, and $\mathrm{P}<0.05$ was considered significant. Correlations of variables with outcomes were expressed as hazard ratio (HR) with $95 \%$ confidence interval (CI). All statistical analyses were performed with SPSS 20.0 (SPSS Inc., Chicago, IL, USA).

\section{Results}

\section{Patients and procedure}

This study enrolled 217 patients, including 189 males and 28 females. The flow chart for patient enrolment is shown in Figure 1. Three patients were lost to follow-up. A total of 75 patients died, 64 of whom died due to BCa during follow-up.

\section{Baseline data}

Table 1 compares the patients' clinical and pathological variables according to BMI category. The mean BMI was $23.3 \mathrm{~kg} / \mathrm{m}^{2}$ and the BMI distribution is shown in Figure 2. Of the 217 patients in this study, $13(6.0 \%), 121(55.8 \%)$, $60(27.6 \%)$ and $23(10.6 \%)$ had a BMI value of $<18.5 \mathrm{~kg} / \mathrm{m}^{2}$ (underweight), $18.5-23.9 \mathrm{~kg} / \mathrm{m}^{2}$ (normal), $24-27.9 \mathrm{~kg} / \mathrm{m}^{2}$ (overweight), and $\geq 28 \mathrm{~kg} / \mathrm{m}^{2}$ (obese), respectively. Patients with low BMI values tended to be older than those with normal or high $\mathrm{BMI}$ values at the time of $\mathrm{RC}(\mathrm{P}=0.009)$ and tended to receive cutaneous ureterostomy as opposed to another urinary diversion procedure $(\mathrm{P}=0.005)$. Analysis of other variables, including sex, stage, tumor size, tumor grade, histology, lymphovascular invasion, and CCI score, uncovered no significant differences between the different BMI categories.

\section{Survival estimates after $R C$}

The Kaplan-Meier survival curves for OS and CSS according to BMI category are displayed in Figure 3. Patients who were underweight or obese tended to have worse survival than those who were of a normal weight or overweight. For underweight, normal, overweight, and obese patients, the 5 -year OS rate was $33 \%, 70.2 \%$, $62.7 \%$, and $38 \%$, respectively, and the 5 -year CSS rate was $40 \%, 73 \%, 66.8 \%$, and $46 \%$, respectively. Subsequently, the patients were divided into three categories: $B M I$ value $<18.5 \mathrm{~kg} / \mathrm{m}^{2}$, BMI value $18.5-27.9 \mathrm{~kg} / \mathrm{m}^{2}$, and BMI value $\geq 28 \mathrm{~kg} / \mathrm{m}^{2}$. The OS and CSS survival curves further illustrated that underweight and obese patients had significantly worse survival than patients who were of a normal weight or overweight (Figure 4).

\section{Prognostic factors associated with OS after RC}

Univariate analysis revealed tumor stage, lymphovascular invasion, urinary diversion type, and three-category variable BMI to be associated with OS. Multivariable analysis further identified extreme $\mathrm{BMI}$ as an independent predictor of OS [BMI $<18.5$ vs. $18.5-27.9 \mathrm{~kg} / \mathrm{m}^{2}$, odds ratio (OR) $=2.675,95 \%$ CI: $1.131-6.327, \mathrm{P}=0.025$; $\mathrm{BMI} \geq 28$ vs. $18.5-$ $27.9 \mathrm{~kg} / \mathrm{m}^{2}, \mathrm{OR}=3.693,95 \%$ CI: $1.589-8.583, \mathrm{P}=0.002$ ], along with tumor stage (stage IV vs. I, OR $=9.247$, 95\% CI: 3.049-28.046, $\mathrm{P}<0.001)$ and urinary diversion type (Bricker vs. ureterostomy, OR $=0.415,95 \%$ CI: $0.213-0.807$, $\mathrm{P}=0.010$; orthotropic bladder vs. ureterostomy, $\mathrm{OR}=0.328$, 95\% CI: 0.151-0.711, $\mathrm{P}=0.005$ ) (Table 2).

\section{Prognostic factors associated with CSS after RC}

Regarding CSS, univariate analysis identified tumor stage, lymphovascular invasion, urinary diversion type, and threecategory variable BMI as significant predictors. Subsequent multivariate analysis showed that extreme BMI was still an independent predictor of CSS (BMI $<18.5$ vs. 18.5 $-27.9 \mathrm{~kg} / \mathrm{m}^{2}$, OR $=3.012,95 \%$ CI: $1.180-7.687, \mathrm{P}=0.021$; $\mathrm{BMI} \geq 28$ vs. $18.5-27.9 \mathrm{~kg} / \mathrm{m}^{2}, \mathrm{OR}=3.801,95 \%$ CI: $1.526-$ 
Table 1 Comparison of clinical/pathological features of the patient cohort according to BMI category

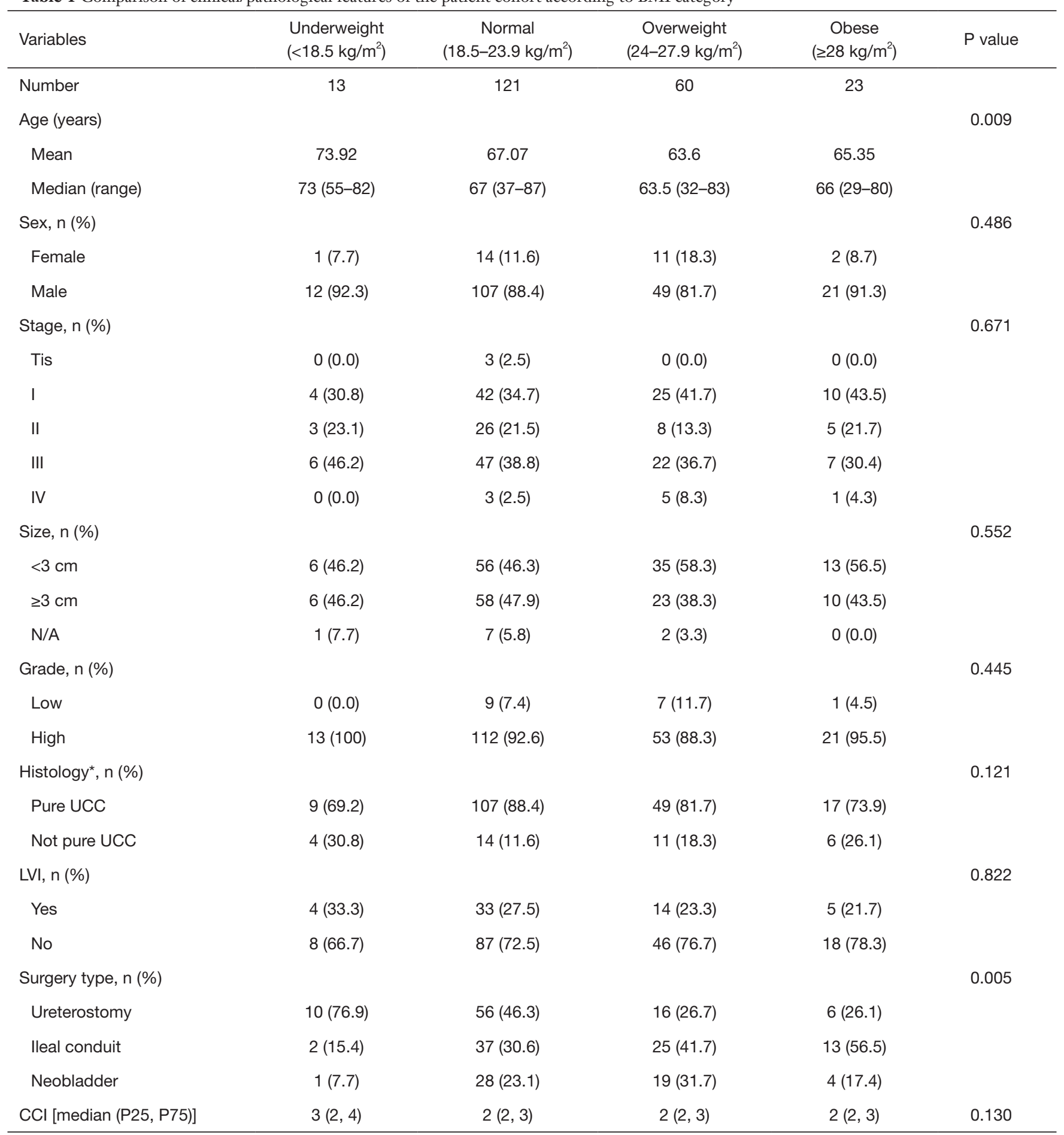

*, pathology showing another histological component such as squamous cell carcinoma or adenocarcinoma was defined as "not pure UCC”. BMI, body mass index; LVI, Iymphovascular invasion; UCC, urothelial cell carcinoma; CCI, Charlson Comorbidity Index. 


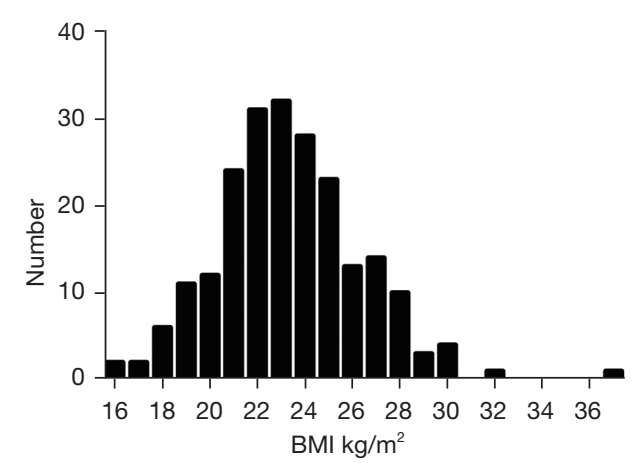

Figure 2 Distribution of BMI values. BMI, body mass index.

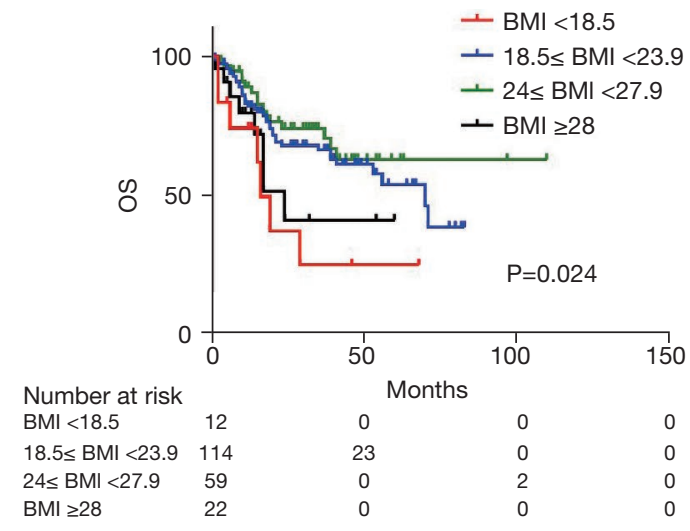

9.469, $\mathrm{P}=0.004$ ), along with tumor stage (stage IV vs. I, $\mathrm{OR}=20.436,95 \% \mathrm{CI}: 5.795-72.066, \mathrm{P}<0.001)$ and urinary diversion type (Bricker vs. ureterostomy, OR $=0.456$, 95\% CI: 0.222-0.934, $\mathrm{P}=0.032$; orthotropic bladder $v s$. ureterostomy, OR =0.295, 95\% CI: 0.127-0.684, P=0.004) (Table 3).

\section{Discussion}

Obesity has become prevalent worldwide and is a growing health problem even in developing countries. The WHO

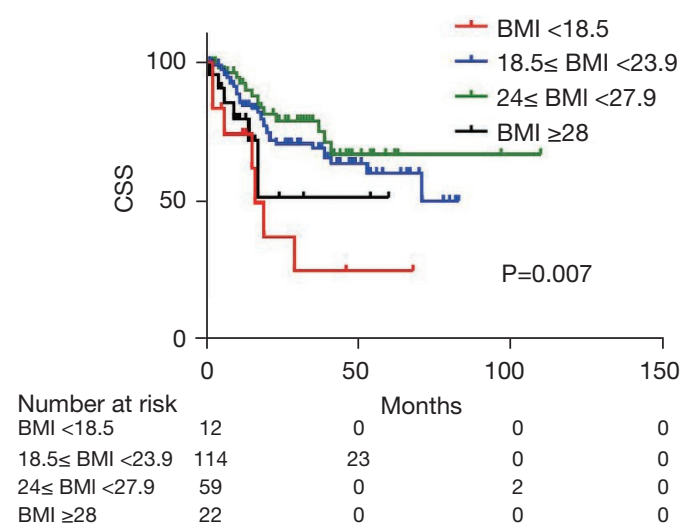

Figure 3 Kaplan-Meier analysis of patient survival after radical cystectomy for bladder cancer according to the four BMI categories. Left: OS; right: CSS. BMI, body mass index; OS, overall survival; CSS, cancer-specific survival.
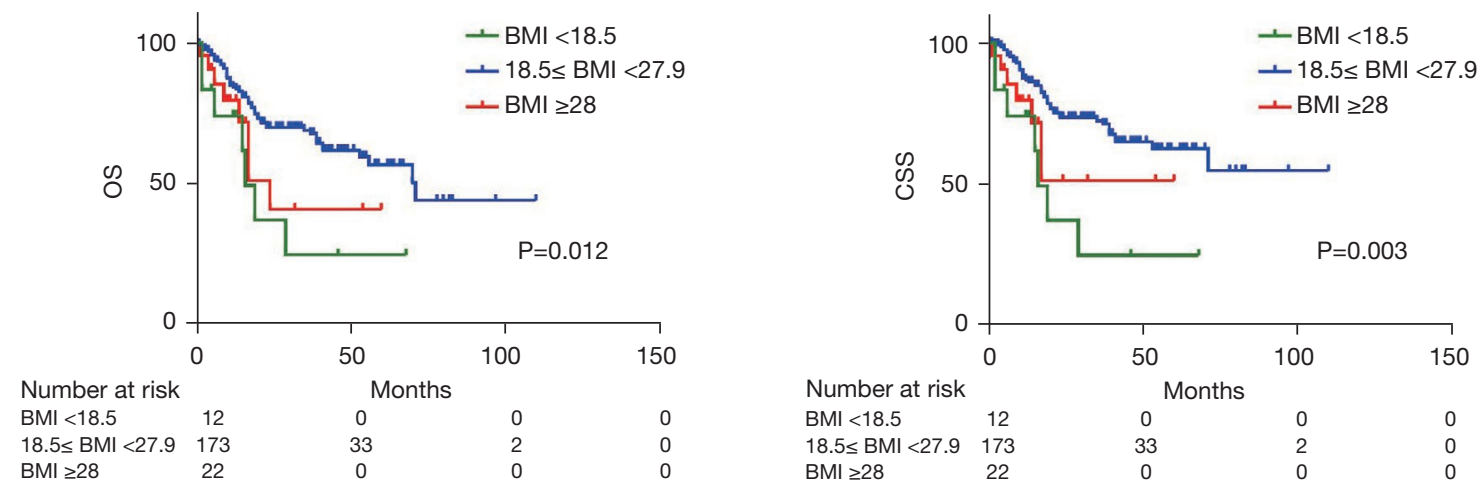

Figure 4 Kaplan-Meier analysis of patient survival after radical cystectomy for bladder cancer according to three BMI categories. Left: OS; right: CSS. BMI, body mass index; OS, overall survival; CSS, cancer-specific survival. 
Table 2 Univariable and multivariable Cox regression models evaluating the OS of patients with bladder cancer after radical cystectomy

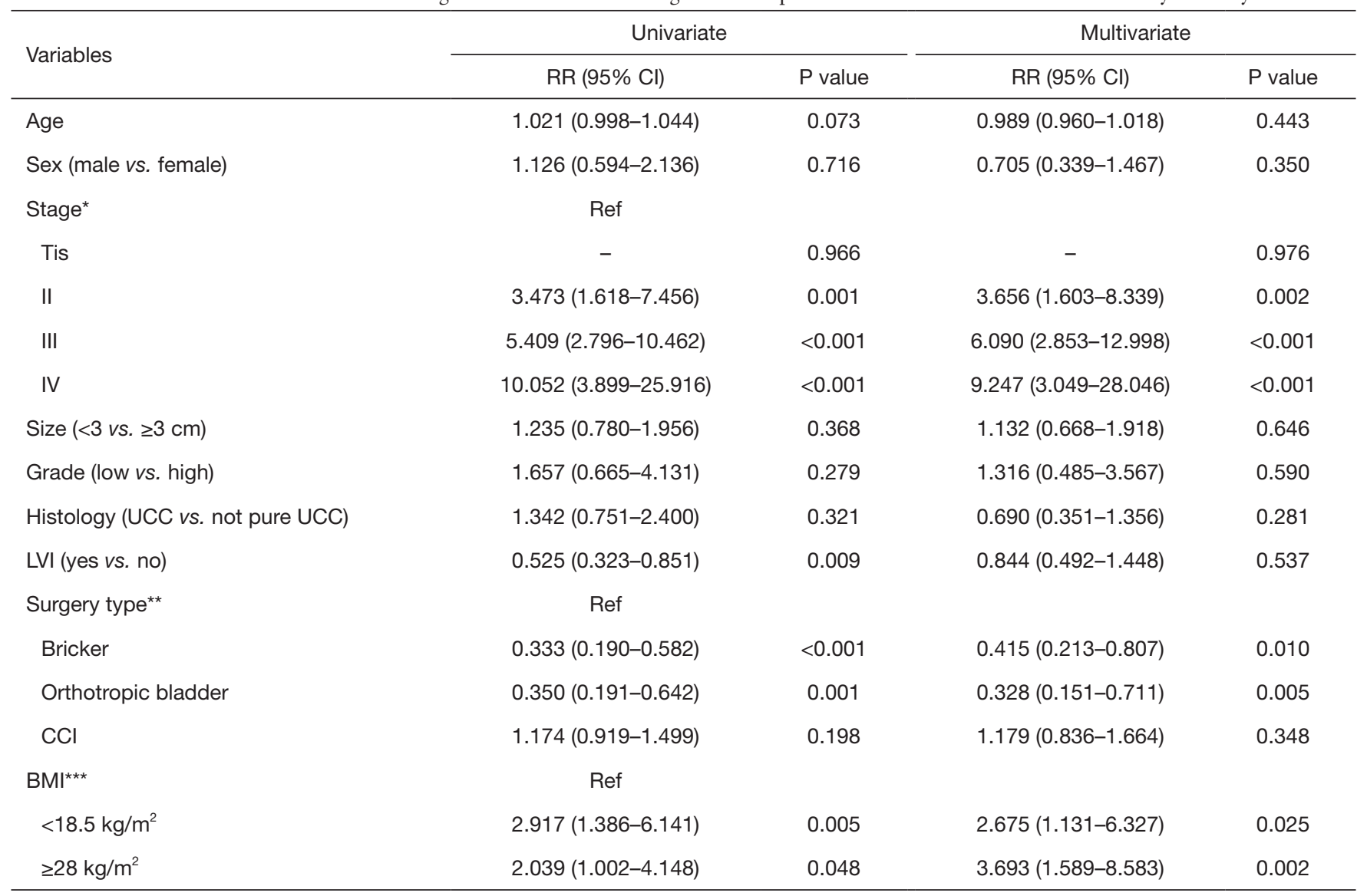

${ }^{*}$, stage I was used as a reference value; ${ }^{* *}$, ureterostomy was used as a reference value; ${ }^{* \star}$, BMl value within $18.5-27.9 \mathrm{~kg} / \mathrm{m}^{2}$ was used as a reference value. OS, overall survival; LVI, lymphovascular invasion; BMI, body mass index; CCl, Charlson Comorbidity index.

criteria define a BMI of 25 to $30 \mathrm{~kg} / \mathrm{m}^{2}$ as overweight and a BMI of over $30 \mathrm{~kg} / \mathrm{m}^{2}$ as obesity (18). Despite the growing influence of Westernized lifestyles and diets in China, the incidence of obesity was only $11.9 \%$ and the average BMI was $23.6 \mathrm{~kg} / \mathrm{m}^{2}$ among adults in 2010-2012 (19). Therefore, the Chinese criteria, which define overweight as BMI $24-28 \mathrm{~kg} / \mathrm{m}^{2}$ and obesity as BMI $\geq 28 \mathrm{~kg} / \mathrm{m}^{2}(19)$, were considered to be more suitable for this study. The participants in our study were first divided into four groups: underweight, normal, overweight, and obese. We found that having a BMI at either end of the scale was associated with a worse survival outcome. Next, we divided the study participants into three groups: two groups of patients with extreme BMI (underweight and obese) and one group of patients with average BMI (normal/overweight). The differences in survival outcome between the patients with extreme BMI and those with average BMI were statistically significant.

For advanced $\mathrm{BCa}, \mathrm{RC}$ and urinary diversion remain the gold standard (20). However, until now, it remained uncertain whether having a high BMI could result in a worse prognosis after cystectomy. A large sample study of 4,118 patients by Chromecki et al. showed that obesity was linked to poor cancer-specific outcomes (13). However, a recent prospective multicenter study of 671 patients showed inconsistent results, even finding that patients with obesity had better OS than patients of a normal weight (14). At present, there are few relevant studies conducted in the Chinese population. Because the BMI classification standard of Chinese people is significantly different from that of the western population, research in Chinese population may be helpful to further evaluate the relationship between BMI and $\mathrm{RC}$ prognosis. The results of the present study in a Chinese population support the view that obesity can lead 
Table 3 Univariable and multivariable Cox regression models evaluating the CSS of patients with bladder cancer after radical cystectomy

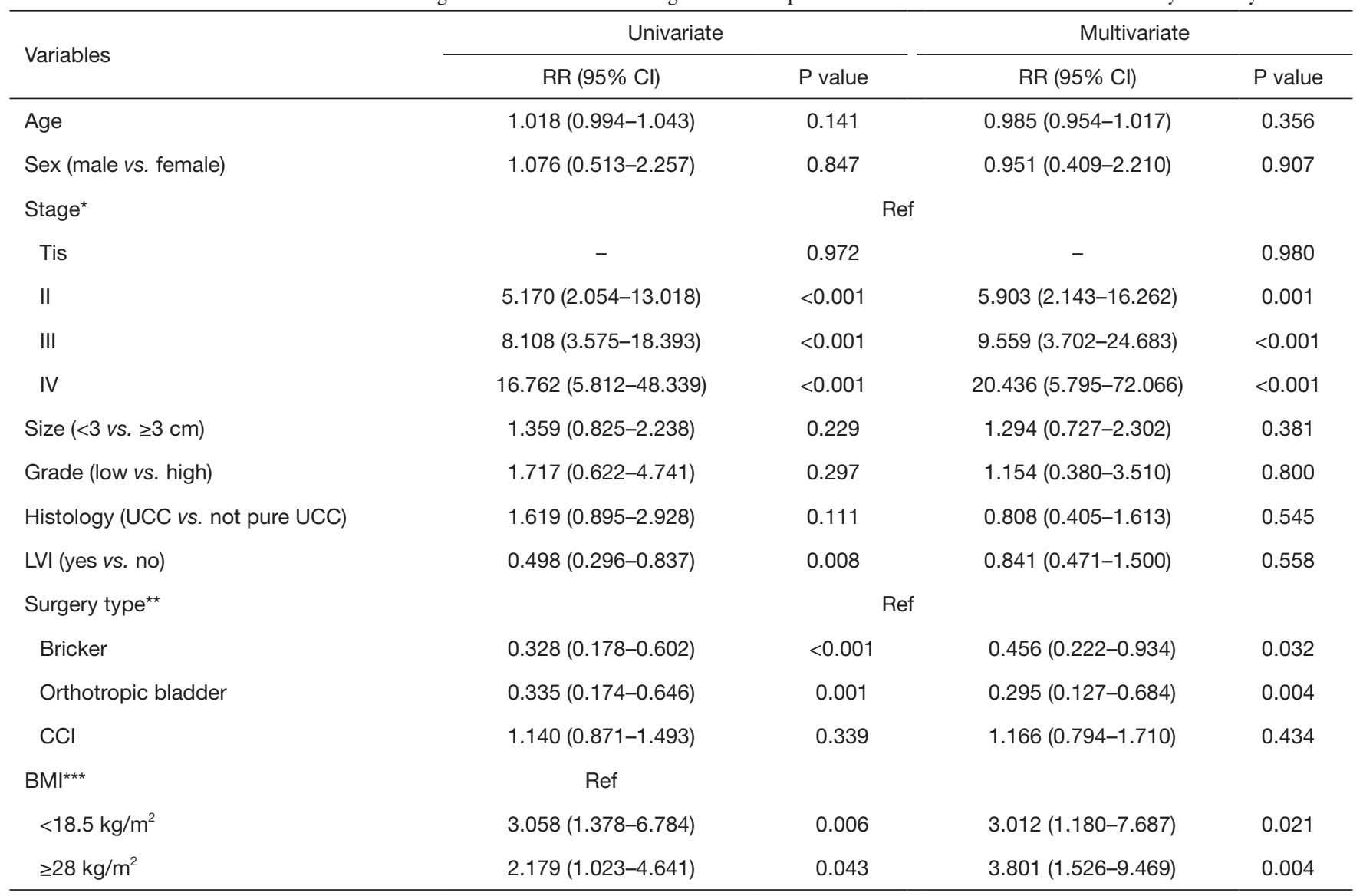

${ }^{*}$, stage I was used as a reference value; ${ }^{* *}$, ureterostomy was used as a reference value; ${ }^{* *}$, BMI value within $18.5-27.9 \mathrm{~kg} / \mathrm{m}^{2}$ was used as a reference value. OS, overall survival; LVI, lymphovascular invasion; BMI, body mass index; CCl, Charlson Comorbidity index.

to a worse prognosis after RC.

The reasons why increased $\mathrm{BMI}$ is related to worse oncological outcomes may be complex. One common explanation is that obese patients have an unclarified anatomy due to excessive fat tissue and are more difficult to operate on, which could result in an increased risk of surgical complications, longer operation times, and more blood loss (21). A study comprising 2,240 patients found that BMI as a continuous variable was an independent predictor of 90 day major complications (22). Another prospective study involving 548 patients who underwent laparoscopic RC also found that high BMI was independently associated with a higher overall risk of postoperative complications (23). However, the occurrence of short-term complications does not necessarily translate to a poor survival outcome. In our study, fatal complications, such as repeated infections or renal dysfunction, were not common in any of the three BMI groups. A large decline in survival in the two extreme BMI groups occurred within the first 12-16 months after surgery, which was in accordance with the observations of a previous report, in which most local recurrence occurred within 6-18 years after cystectomy and $90 \%$ of distant recurrence appeared within the first 2 years (24). In our study, the $\mathrm{OS}$ and CSS rates were similar, which means that $\mathrm{BCa}$ progression was responsible for most of the deaths recorded.

Another explanation for obesity's association with poor oncological outcomes may lie in its close relationship with inflammation. The biological mechanism by which obesity affects cancer development involves several pathways, including the insulin/insulin-like growth factor pathway, sex steroids, adipokines, and a state of chronic inflammation (25). Considering that sex differences contribute to a poor prognosis after RC, obesity might lead to hormonal changes, as excessive lipids cells can produce estrogen (26). The 
increased expression of estrogen receptor beta has been implicated in the development of urothelial cancer (27). There is potential for differential expression of this receptor in patients with obesity; however, this has not specifically been studied. Moreover, obesity can increase the levels of insulin, insulin-like growth factor-1, and inflammatory cytokines, which exert mitogenic, anti-apoptotic proangiogenic functions and facilitate tumor growth (28).

One important finding of our study is that being underweight can also lead to a poor prognosis. The reason might be that underweight patients were older and tended to undergo ureterostomy. Multiple studies have evidenced that having underweight status predicts a poor prognosis of other cancers, including gastric and colorectal cancer $(29,30)$. Theoretically, low body mass is usually an indication to low serum albumin and poor nutritional status. Moreover, excessive weight loss might be associated with cancer cachexia, which is a complex metabolic condition characterized by loss of skeletal muscle and body weight that develops in progressive disease (31).

Our study has some limitations. First, it is a retrospective design and is hard to avoid selection bias. Second, BMI alone cannot fully reflect a patient's adiposity status. Waist circumference and the waist-to-hip ratio are commonly used in conjunction with BMI to approximate central adiposity and intra-abdominal visceral fat, which are now considered to be equally crucial indicators of health status. Third, the study did not include serum markers to reflect nutrition status. Nevertheless, our study adds more evidence of the importance of BMI to patient outcomes after RC, which has been rarely studied in Chinese population. According to the results of this research, for patients who are diagnosed with bladder cancer and potentially need to undergo RC, more attention should be paid to maintaining a normal BMI level.

\section{Conclusions}

Our results suggest that Chinese patients who are underweight or obese have a worse prognosis after undergoing $\mathrm{RC}$ for $\mathrm{BCa}$ than patients who are normal weight or overweight. Therefore, in addition to conventional risk factors, BMI could serve as a predictor of $\mathrm{BCa}$ prognosis. Multicenter prospective research is warranted to confirm these conclusions.

\section{Acknowledgments}

Funding: This work was supported by a grant from the
National Natural Science Foundation of China (grant no. 81001134).

\section{Footnote}

Reporting Checklist: The authors have completed the STROBE reporting checklist. Available at https://dx.doi. org/10.21037/tau-21-871

Data Sharing Statement: Available at https://dx.doi. org/10.21037/tau-21-871

Conflicts of Interest: All authors have completed the ICMJE uniform disclosure form (available at https://dx.doi. org/10.21037/tau-21-871). The authors have no conflicts of interest to declare.

Ethical Statement: The authors are accountable for all aspects of the work in ensuring that questions related to the accuracy or integrity of any part of the work are appropriately investigated and resolved. This study was conducted in accordance with the Declaration of Helsinki (as revised in 2013) and was approved by the Ethics Committee of Shanghai Tenth People's Hospital (SHSYIEC-4.1/20-24/01). Informed consent was taken from all individual participants.

Open Access Statement: This is an Open Access article distributed in accordance with the Creative Commons Attribution-NonCommercial-NoDerivs 4.0 International License (CC BY-NC-ND 4.0), which permits the noncommercial replication and distribution of the article with the strict proviso that no changes or edits are made and the original work is properly cited (including links to both the formal publication through the relevant DOI and the license). See: https://creativecommons.org/licenses/by-nc-nd/4.0/.

\section{References}

1. Sung H, Ferlay J, Siegel RL, et al. Global Cancer Statistics 2020: GLOBOCAN Estimates of Incidence and Mortality Worldwide for 36 Cancers in 185 Countries. CA Cancer J Clin 2021;71:209-49.

2. Mao W, Huang X, Wang L, et al. Circular RNA hsa circ_0068871 regulates FGFR3 expression and activates STAT3 by targeting miR-181a-5p to promote bladder cancer progression. J Exp Clin Cancer Res 2019;38:169.

3. Pelucchi C, Bosetti C, Negri E, et al. Mechanisms of 
disease: The epidemiology of bladder cancer. Nat Clin Pract Urol 2006;3:327-40.

4. Smith M, Zhou M, Whitlock G, et al. Esophageal cancer and body mass index: results from a prospective study of 220,000 men in China and a meta-analysis of published studies. Int J Cancer 2008;122:1604-10.

5. Aune D, Greenwood DC, Chan DS, et al. Body mass index, abdominal fatness and pancreatic cancer risk: a systematic review and non-linear dose-response metaanalysis of prospective studies. Ann Oncol 2012;23:843-52.

6. Hu MB, Liu SH, Jiang HW, et al. Obesity affects the biopsy-mediated detection of prostate cancer, particularly high-grade prostate cancer: a dose-response meta-analysis of 29,464 patients. PLoS One 2014;9:e106677.

7. Wang K, Chen X, Gerke TA, et al. BMI trajectories and risk of overall and grade-specific prostate cancer: An observational cohort study among men seen for prostatic conditions. Cancer Med 2018;7:5272-80.

8. Harriss DJ, Atkinson G, George K, et al. Lifestyle factors and colorectal cancer risk (1): systematic review and metaanalysis of associations with body mass index. Colorectal Dis 2009; 11:547-63.

9. Sung H, Siegel RL, Torre LA, et al. Global patterns in excess body weight and the associated cancer burden. CA Cancer J Clin 2019;69:88-112.

10. Alfred Witjes J, Lebret T, Compérat EM, et al. Updated 2016 EAU Guidelines on Muscle-invasive and Metastatic Bladder Cancer. Eur Urol 2017;71:462-75.

11. Kwon T, Jeong IG, You D, et al. Obesity and prognosis in muscle-invasive bladder cancer: the continuing controversy. Int J Urol 2014;21:1106-12.

12. Dabi Y, Rouscoff Y, Anract J, et al. Impact of body mass index on the oncological outcomes of patients treated with radical cystectomy for muscle-invasive bladder cancer. World J Urol 2017;35:229-35.

13. Chromecki TF, Cha EK, Fajkovic H, et al. Obesity is associated with worse oncological outcomes in patients treated with radical cystectomy. BJU Int 2013;111:249-55.

14. Gierth M, Zeman F, Denzinger S, et al. Influence of Body Mass Index on Clinical Outcome Parameters, Complication Rate and Survival after Radical Cystectomy: Evidence from a Prospective European Multicentre Study. Urol Int 2018;101:16-24.

15. Ahmadi N, Clifford TG, Miranda G, et al. Impact of body mass index on robot-assisted radical cystectomy with intracorporeal urinary diversion. BJU Int 2017;120:689-94.

16. Bono OJ, Poorman GW, Foster N, et al. Body mass index predicts risk of complications in lumbar spine surgery based on surgical invasiveness. Spine J 2018;18:1204-10.

17. Zhou BF. Effect of body mass index on all-cause mortality and incidence of cardiovascular diseases--report for metaanalysis of prospective studies open optimal cut-off points of body mass index in Chinese adults. Biomed Environ Sci 2002;15:245-52.

18. Hou X, Liu Y, Lu H, et al. Ten-year changes in the prevalence of overweight, obesity and central obesity among the Chinese adults in urban Shanghai, 1998-2007 - comparison of two cross-sectional surveys. BMC Public Health 2013;13:1064.

19. Pan XF, Wang L, Pan A. Epidemiology and determinants of obesity in China. Lancet Diabetes Endocrinol 2021;9:373-92.

20. Mao W, Xie J, Wu Y, et al. Cost-effectiveness analysis of two kinds of bladder cancer urinary diversion: Studer versus Bricker. Transl Androl Urol 2020;9:1113-9.

21. Crivelli JJ, Xylinas E, Kluth LA, et al. Effect of smoking on outcomes of urothelial carcinoma: a systematic review of the literature. Eur Urol 2014;65:742-54.

22. Osawa T, Lee CT, Abe T, et al. A Multi-Center International Study Assessing the Impact of Differences in Baseline Characteristics and Perioperative Care Following Radical Cystectomy. Bladder Cancer 2016;2:251-61.

23. Albisinni S, Oderda M, Fossion L, et al. The morbidity of laparoscopic radical cystectomy: analysis of postoperative complications in a multicenter cohort by the European Association of Urology (EAU)-Section of Uro-Technology. World J Urol 2016;34:149-56.

24. Huguet J. Follow-up after radical cystectomy based on patterns of tumour recurrence and its risk factors. Actas Urol Esp 2013;37:376-82.

25. Renehan AG, Zwahlen M, Egger M. Adiposity and cancer risk: new mechanistic insights from epidemiology. Nat Rev Cancer 2015;15:484-98.

26. Liu S, Yang T, Na R, et al. The impact of female gender on bladder cancer-specific death risk after radical cystectomy: a meta-analysis of 27,912 patients. Int Urol Nephrol 2015;47:951-8.

27. Miyamoto H, Yao JL, Chaux A, et al. Expression of androgen and oestrogen receptors and its prognostic significance in urothelial neoplasm of the urinary bladder. BJU Int 2012;109:1716-26.

28. Lin C, Travis RC, Appleby PN, et al. Pre-diagnostic circulating insulin-like growth factor-I and bladder cancer risk in the European Prospective Investigation into Cancer and Nutrition. Int J Cancer 2018;143:2351-8. 
29. Kim CH, Park SM, Kim JJ. The Impact of Preoperative Low Body Mass Index on Postoperative Complications and Long-term Survival Outcomes in Gastric Cancer Patients. J Gastric Cancer 2018;18:274-86.

30. Komatsu S, Kosuga T, Kubota T, et al. Preoperative Low Weight Affects Long-term Outcomes Following Curative Gastrectomy for Gastric Cancer. Anticancer Res
2018;38:5331-7.

31. Kim SI, Kim HS, Kim TH, et al. Impact of underweight after treatment on prognosis of advanced-stage ovarian cancer. J Immunol Res 2014;2014:349546.

(English Language Editor: J. Reylonds)
Cite this article as: Huang X, Jin S, Liu S, Geng J. Extreme body mass index is associated with poor survival outcomes after radical cystectomy: a retrospective cohort study in a Chinese population. Transl Androl Urol 2021;10(10):3852-3861. doi: 10.21037/tau-21-871 